\title{
FIXIDEZ E A DESCONSTRUÇ̃̃O: UMA DISCUSSÃO SOBRE A IDENTIDADE LÉSBICA INVISIBILIZADA NAS ARTES
}

\author{
FIXING AND DECONSTRUCTION: A DISCUSSION ON LESBIAN IDENTITY INVISIBILIZED IN THE ARTS
}

\section{RESUMO}

Este artigo traz uma reflexão sobre a importância do teatro para o debate da identidade lésbica no Brasil, com outras artes como as telenovelas brasileiras e a fotografia, que apresenta elementos da cultura afro, base da identidade nacional, bem como traz o estudo de caso da Parada do Orgulho Gay 2017. Para tanto, adotou-se o método indutivo em diálogo analítico com a revisão literária moderna dos estudos queer, especialmente sobre a identidade lésbica. Assim, propõe-se um chamamento para a reflexão e a pesquisa científica sobre a arte lésbica no Brasil, bem como sobre sua visibilidade e representatividade social. Como resultado, há o apontamento das identidades lésbicas que não são devidamente representadas nas artes cênicas brasileiras, tal qual acontece em trabalhos estrangeiros sobre a temática. Levanta-se, também, a provocação para a discussão e a pesquisa que é praticamente inexistente na perspectiva aqui relatada.

Palavras-chave: Identidade. Gênero. Lésbica. Arte.

\begin{abstract}
This article presents a reflection on the importance of theater for the debate of lesbian identity in Brazil, dialogues with other arts such as Brazilian soap opera and photography, which presents elements of the Afro culture, the basis of Brazilian identity, as well as the study of case of the Gay Pride Parade 2017. For this purpose, the inductive method was adopted in analytical dialogue with the modern literary revision of queer studies, especially on lesbian identity. Thus, it is proposed an invitation to reflection and scientific research on lesbian art in Brazil, as well as on its visibility and social representativeness. As a result, there is an indication of the lesbian identities that are not properly represented in the Brazilian performing arts, as it happens in foreign works on the subject. It also encourages a discussion and a research of this topic, which is practically non-existent in the perspective reported here.
\end{abstract}

Keywords: Identity. Gender. Lesbian. Art.

Camila Karla Grillo

Universidade de São Paulo (USP). E-mail: camilagrillo@usp.br

Ricardo Lanzarini

Universidade Federal do Rio Grande do Norte (UFRN) e Universidade de São Paulo (USP).

E-mail: ricardolanzarini@ccsa.ufrn.br 


\section{Introdução}

Não há como pensar a identidade lésbica no século XXI sem considerar os estudos culturais, de gênero e sexualidade, especialmente sob o aspecto das artes, lugar de construção de memórias coletivas e possíveis transformações pessoais e sociais. Por isso, se faz importante abordar os diferentes instrumentos, como o teatro que, histórica e artisticamente, se destaca por ser considerado uma ferramenta social para discussão de muitos temas ligados a desigualdades, como as questões de classe, raça e gênero, além dos direitos das mulheres e, por isso, pode possibilitar um espaço para o debate lésbico, seja para desconstruir estereótipos, seja para levar ao público a visibilidade deste universo marginalizado.

Outros mecanismos têm sido fundamentais para que esta discussão aconteça como a mobilização de grupos criados nas redes sociais para o engajamento feminino, as telenovelas brasileiras, que inserem personagens LGBTQIs ${ }^{1}$ em seus enredos, bem como as artes fotográficas que possibilitam, entre diferentes temáticas, um enquadramento de identidades lésbicas a fim de que o público tenha um registro deste universo. Porém, mesmo com estas diferentes expressões o teatro, como arte efêmera, torna-se um local em que diversos conflitos são apresentados em textos e disposições cênicas condensados na construção de personagens. Logo, estelugar detransformações oferece um espaço para expressar sentimentos, a exemplo de insatisfações, medos e repressões vivenciados por homossexuais, mais especificamente, pelos homens que têm maior visibilidade e oportunidade midiática devido às questões culturais brasileiras, que incluem um forte machismo opressor da sexualidade masculina e fetichista sobre a figura da mulher, consumida como objeto de prazer.

Nessa perspectiva, o teatro brasileiro tem sido um ambiente para a construção de alguns espetáculos voltados para o universo gay. Basta verificar as sinopses, nos guias culturais de jornais na cidade de São Paulo ou sites com a divulgação de peças LGBTQIs, que ganham maior visibilidade midiática durante a semana do Orgulho Gay, como aconteceu em $2017^{2}$. Esta grande metrópole concentra muitos trabalhos com assuntos ligados ao gênero, porém, cabe aqui a questão: onde estão as temáticas lésbicas no teatro? Para responder ao debate, tomou-se como estudo de caso a Parada LGBTQI 2017, que não apresentou sequer uma peça lésbica, mas sim, 19 espetáculos abordando temáticas no universo trans, queer e gay.

Para chegar a esta análise, foi realizado um levantamento das sinopses das peças divulgadas na internet, e a partir do levantamento de palavras-chaves nos textos publicados, apresenta-se aqui um diálogo analítico em que as identidades lésbicas são discutidas por meio da revisão literária da perspectiva dos estudos queer, bem como os estudos lésbicos. Logo, é observado o apagamento lésbico no teatro, principalmente dentro de um evento com proposta de visibilidade LGBTQI.

1 Lésbica, gays, bissexuais, queer e intersexuais.

2 No clima da Parada do Orgulho LGBT, peças discutem diversidade sexual e homofobia. Disponível em: <http://guia.folha.uol.com.br/teatro/2017/o6/no-clima-da-parada-do-orgulho-lgbt-pecas-discutemdiversidade-sexual-e-homofobia.shtml> Acesso em: 03 dez. 2017. 
Sobre esta questão, é possível levantar algumas hipóteses tradicionais para essa invisibilidade da figura feminina, como o machismo já citado ou a falta de interesse de cunho capitalista por produções que foquem no universo da mulher por ela mesma, pois a erotização lésbica no Brasil aparece frequentemente em produções pornográficas destinadas aos homens, fato que transfigura o prazer lésbico para a satisfação do masculino heterossexual. Qual seria, então, a identidade lésbica representada em cena? Quais discursos são utilizados neste espaço simbólico?

Para responder a estas questões e buscar a causa fundamental deste apagamento lésbico no teatro, seria preciso dar voz a atrizes e compreender quais questões e conflitos permeiam este universo, já que muito se fala em direito das mulheres e é preciso considerar que existem diferentes identidades a serem representadas, mesmo dentro do universo lésbico. Portanto, há um fator primordial que é a reflexão sobre o sujeito de quem se fala e como se configura essa identidade. Partindo desta premissa, esta discussão das identidades se faz fundamental antes da própria análise sobre os espetáculos gays que foram realizados durante as festividades que antecederam a Parada durante o ano de 2017.

Quando falamos na lésbica, há a compreensão de que existe uma unicidade entre todas as mulheres homoafetivas. Porém, é preciso trazer à tona a discussão da constituição desse sujeito, como apresenta Michel Foucault (1995), através de três maneiras com o qual o sujeito foi definido.

O primeiro é o modo da investigação, que tenta atingir o estatuto de ciência, como, por exemplo, a objetivação do sujeito do discurso na grammaire générale, ${ }^{\prime}$ na filologia e na lingüística. Ou, ainda, a objetivação do sujeito produtivo, do sujeito que trabalha, na análise das riquezas e na economia. Ou, um terceiro exemplo, a objetivação do simples fato de estar vivo na história natural ou na biologia (ibidem, p. 231).

Em todas essas investigações, apresenta-se a definição de um sujeito que é produzido pelo discurso social, isto é, um sujeito objetivado por determinadas instâncias, por aquilo que é descrito e imposto como gerador de uma "verdade" e um "saber" que condiciona esse sujeito por intermédio de relações de poder. "Por mais que o discurso seja aparentemente bem pouca coisa, as interdições que o atingem revelam logo, rapidamente, sua ligação com o desejo e com o poder." (FOUCAULT, 1996, p.10). Assim, esse sujeito, que possui um lugar e precisa ser definido no tempo e no espaço, revela-se como o sujeito do iluminismo4. Ou seja, há uma fixidez desse sujeito que é produzido por aquilo que é legitimado pelas instituições, a exemplo da medicina, da ciência e da religião dominantes em cada cenário histórico-cultural.

3 Em francês, no original que em sua tradução significa "gramática geral".

4 O Iluminismo foi um movimento do século XVII e está ligado a revolução científica, tendo como base a razão como meio de produzir verdade. 
Essa legitimação dos discursos toma forma pela confissão, ato que Foucault (1996) descreve como a ação "em que as condutas proibidas eram nomeadas, classificadas, hierarquizada, e da maneira a mais explícita até a aparição inutilmente mais tímida, e retardada, da temática sexual na medicina e na psiquiatria do século XIX [...]". (ibidem, p. 61). Logo, a sexualidade passou a ser confessada a instâncias morais e religiosas. "O sexo, segundo a nova pastoral, não deve mais ser mencionado sem prudência; mas seus aspectos, suas correlações, seus efeitos devem ser seguidos até as mais finas ramificações [...]" (FOUCAULT, 1988, p. 22). Assim, da proibição passou-se à confissão, como uma forma de legitimação dos discursos, através das instâncias de poder, definidoras daquilo que é considerado como normalidade.

No universo homoafetivo, vê-se um sujeito que não está localizado no binarismo heteronormativo como homem/mulher e, por isso, está fora da caixinha 5 . Ao assumir a sua identidade, ele procura legitimar a prática homoerótica e, por esta condição, não está configurado dentro do padrão de relações consideradas "normais". Isso posto, entende-se que, o sujeito considerado "normal" é aquele que segue as normas de conduta social já determinadas em seu grupo de origem. Logo, "[...] a norma não visa excluir ou rejeitar, antes é a pedra de toque de um exame perpétuo de um campo de regularidade dentro do qual se analisa incessantemente cada indivíduo para julgar se ele é conforme a regra ou a norma hegemônica” (MISKOLCI, 2003, p. 110). Consequentemente, identidades paralelas à norma são reprimidas porque não estão enquadradas nas caixinhas da normalidade. No caso de um (a) transexual, por exemplo, ao se decidir fazer uma cirurgia genital ou a mudança de nome social, será necessário confessar-se com médicos, psiquiatras, psicólogos, advogados e com o ministério público. Logo, esses sujeitos passam pelo processo de aprovação ou reprovação das Instituições que, quando muito, os designam com alguma anomalia para justificar o que está fora da norma.

A força reguladora do CID-10, do DSM-IV edo SOC pode sersentida com toda dramaticidade quando referenciada a sujeitos concretos. Nas díades que se multiplicam em hospitais que atendem às pessoas transexuais, nas esferas dos micropoderes, nas demandas judiciais por mudanças de nome e sexo nos documentos, se pode sentir o poder/saber médico atuando, distribuindo normalidades e produzindo anomalias (BENTO, 2008, p.121-122).

Este "poder/saber" passa a ser o determinador da verdade sobre a identidade e sobre o corpo desse sujeito, motivo este que por muitas vezes, manifesta situações de conflitos sociais, principalmente do ponto de vista do determinismo biológico.

Na visão de Stuart Hall (2014) os sujeitos podem ser compreendidos por três concepções de identidade, a exemplo do sujeito do iluminismo, que era centrado em si e unificado, enquanto que o sujeito sociológico trazia sua identidade costurada à estrutura e era fundamentado na socialização. Após estas construções, surge o sujeito

5 Conceito antropológico entendido como o espaço de fixidez estabelecido para a sexualidade e o gênero, baseados no binarismo homem/mulher. 
pós-moderno que se apresenta como ausente de identidade fixa, ou seja, em constante transformação identitária.

O sujeito assume identidades diferentes em diferentes momentos, identidades que não são unificadas ao redor de um "eu" coerente. Dentro de nós há identidades contraditórias, empurrando em diferentes direções, de tal modo que nossas identificações estão sendo continuamente deslocadas (ibidem, p. 13).

Este sujeito que é interpelado por diferentes atravessamentos, apresenta-se descentrado. Hall cita um conceito de "deslocamento" de Ernest Laclau (1990) para definir este sujeito. "Uma estrutura deslocada é aquela cujo centro é deslocado, não sendo substituído por outro, mas por uma pluralidade de centros de poder". (HALL, 2014, p.16). Então, não há uma estrutura fixa que define esse sujeito, constantemente transpassado pelas modificações culturais ao longo do tempo, de identidade fluída e com variação constante.

Ao longo do processo histórico de formação das sociedades modernas, o sujeito foi descentrado em diferentes fases que foram desde o pensamento marxista, no século XIX, até a globalização dos dias atuais; e que está, ainda, em busca de representação de suas identidades.

[...] As pessoas não identificam mais os seus interesses sociais exclusivamente em termos de classe; a classe não pode servir como um dispositivo discursivo ou uma categoria mobilizadora através da qual todos os variados interesses e todas as variadas identidades das pessoas possam ser reconciliadas e representadas (ibidem, p. 21).

Por conseguinte, a luta de classe não pode responder a inúmeras questões que abrangem as diferentes mulheres em suas dimensões de raça, gênero e geração. O sujeito busca sua representatividade na diferença, ou seja, no contexto aqui apresentado, dentro da categoria mulher. Porém não há como criar definições para um tipo específico de categoria sem levar em consideração que existem mulheres diferentes constituindo subcategorias com variações de etnias, gerações, classes sociais ou de gênero como heterossexuais, lésbicas e transexuais. Desse modo, pode-se afirmar que "ser lésbica" é uma identidade social e pessoal, mas não fixa e atravessada por outras identidades ao longo de sua vivência social e sexual.

É assim que se apresentam os sujeitos plurais. Cabe trazer a reflexão de que os sujeitos constituídos por identidades fixas, não são os sujeitos da pós-modernidade, ou seja, neste tempo histórico, existe um grande conflito entre os discursos que tentam produzir um sujeito fixo, com a identidade fluída de sujeitos que não se inserem nas caixinhas, como acontece com a lésbica que não seapresenta enquadrada na forma binária estabelecida pela heteronormatividade, mas que, devido a um posicionamento político, revela-se de forma fixa como estratégia de visibilidade. Nesse sentido, a arte aparece para que esse lugar de fala possa ser utilizado para combater a marginalização desses sujeitos. 


\section{Resistência como travessia}

Para pensar a arte como um meio de visibilidade lésbica, é preciso compreender qual é o lugar da mulher em meio a diferentes manifestações artísticas. A busca por mais espaços tem levado artistas a tomar iniciativas de mobilização das mulheres. É o caso do Mulheres do Teatro Brasil ${ }^{6}$, grupo fechado disponível na rede social Facebook e que abarca em torno de $1576^{7}$ mulheres que são profissionais de teatro (atrizes, diretoras e produtoras, além de especialistas que atuam com iluminação, cenografias e sonoplastia). Para descrever as regras de convivência nesse espaço digital, uma das idealizadoras do grupo fez uma postagem em que foi estabelecido que o local é voltado apenas para mulheres das artes, como demonstra a Figura 01.

Figura 1: Postagem inserida no grupo Mulheres do Teatro Brasil na rede social Facebook (2017)

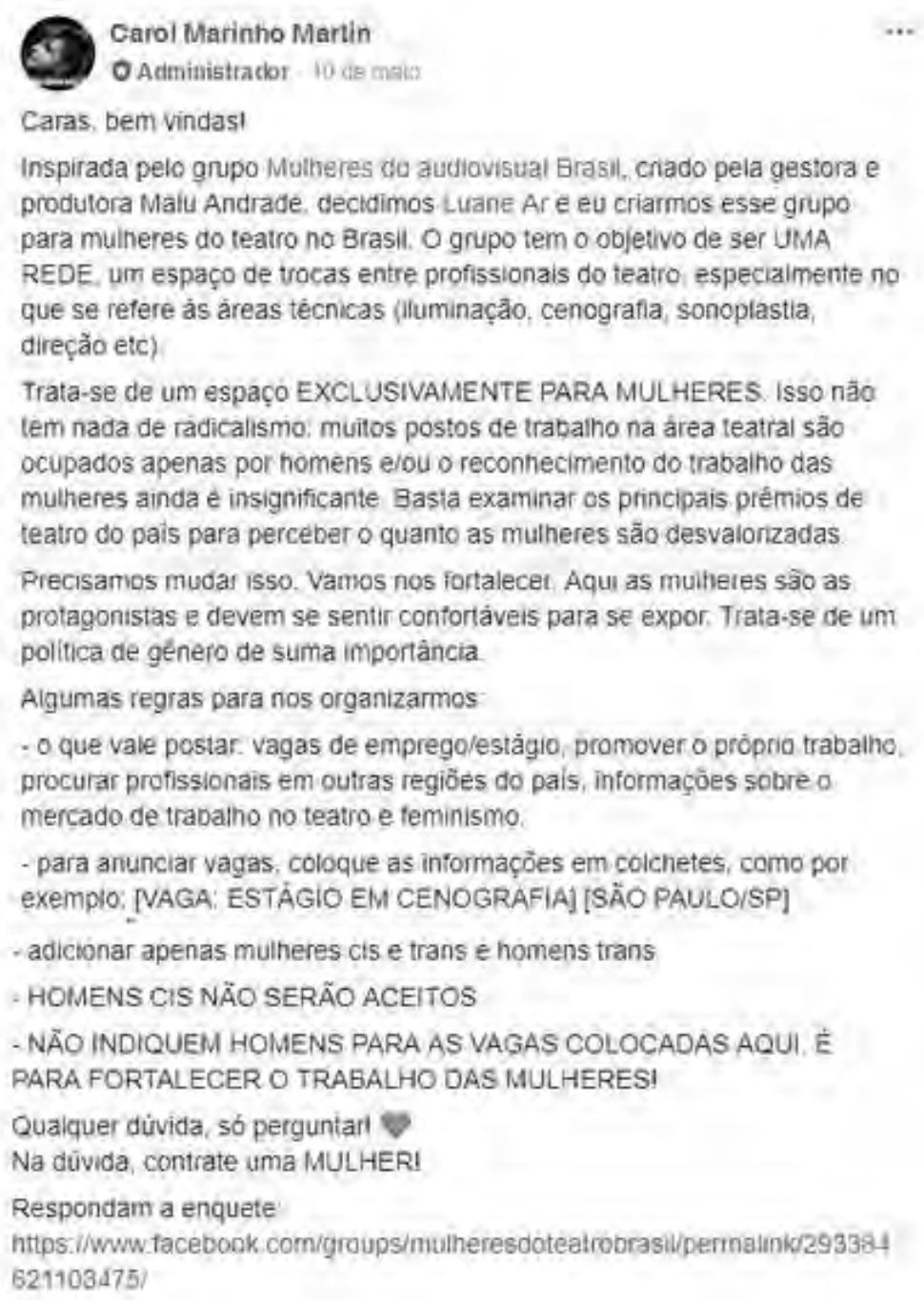

Disponível em:<https://www.facebook.com/groups/mulheresdoteatrobrasil/> Acesso em: 13 nov. 2017.

6 Disponível em: <https://www.facebook.com/groups/mulheresdoteatrobrasil/?multi_ permalinks=354747371633866\&notif_id=1507728852465922\&notif_t=group_activity > Acesso em: 12 out. 2017.

7 Este dado foi consultado em o9 set. 2017. 
A criação deste grupo também reforça o poder que o teatro tem de mobilizar e transformar as questões da sociedade, principalmente as que se referem às mulheres. Além das expressões lúdicas, abre-se um espaço para o debate e militância. Portanto, apresenta-se também a necessidade de uma organização que legitime o papel da mulher nas diferentes esferas de atuação no campo das artes.

Esta forma de organização estabelece um chamado para que as mulheres das artes cênicas possam juntar forças e lutar pela ocupação de seus espaços de pertencimento. Também revela a existência da busca por estratégias de resistência que são criadas para combater o machismo, o apagamento presente no decorrer da história e a falta de espaços no campo das artes para que mais mulheres possam atuar, dirigir e produzir trabalhos que estabeleçam a visibilidade feminina.

Curioso é que ainda hoje as mulheres enfrentam algumas das dificuldades encontradas por suas precursoras no século XIX. Se antes lhes eram vedados o acesso à formação escolar e a divulgação de seus trabalhos, atualmente continuam minoria nas historiografias, nas instituições responsáveis pela canonização/ monumentalização e ainda devem mobilizar pesados trunfos para obter autoridade ou respeitabilidade no campo simbólico. É certo que ocorreram conquistas, um número maior de mulheres forçou passagem e ajudou a construir um espaço que, embora restrito, demonstra que sua competência já não pode ser mais questionada como nos séculos anteriores (BRITTO e MOREIRA, 2014, p. 8).

Nesse sentido, esta mobilização no universo digital, foi criada como uma rede em que é estabelecido que não há lugar para homens, o que possibilita maior militância e organização para o fortalecimento de artistas, que por muitas vezes, não têm seus trabalhos reconhecidos, principalmente no que se refere à hegemonia masculina.

O embate entre o binarismo homem/mulher mostra não somente as diferenças nas relações de trabalho, mas também nas questões que envolvem a biologia. A luta por conquista de direitos é bastante presente nos movimentos feministas e leva à reflexão sobre a questão do gênero. Linda Nicholson (2000) traz duas definições antagônicas sobre o significado desta palavra.

Deum lado, o "gênero" foi desenvolvido eésempre usado em oposição para descrever o que é socialmente construído, em oposição ao que é biologicamente dado. Aqui, "gênero" é tipicamente pensado como referência a personalidade e comportamento, não ao corpo; "gênero" e sexo" são, portanto, compreendidos como distintos. De outro lado, "gênero" tem sido cada vez mais usado como referência a qualquer construção social que tenha a ver com a distinção masculino/ feminino, incluindo as construções que separam corpos "femininos" de corpos "masculinos". Esse último uso apareceu quando muitos perceberam que a sociedade forma não só a personalidade e o comportamento, mas também as maneiras como o corpo aparece. (ibidem, p. 1) 
Neste momento o gênero se apresenta, de um lado, como um comportamento diferente do sexo e, de outro, determinado pelo corpo, ou seja, a biologia é vista como verdade ao estabelecer uma diferença entre o masculino e feminino por meio dos órgãos genitais. Então, o determinismo biológico impõe uma diferença entre o homem e a mulher através de uma configuração corporal que leva a seguinte pergunta: éa biologia ou a cultura que determina quem é homem ou mulher? "Por causa dessa assunção implícita no sentido de fincar na biologia as raízes das diferenças entre mulheres e homens, o conceito de "sexo" colaborou com a ideia da imutabilidade dessas diferenças e com a desesperança de certas tentativas de mudanças” (ibidem, p. 2).

Ao olharmos do ponto de vista do sexo como feminino e masculino, esta visão binária continua a estabelecer padrões entre homens e mulheres que se constituem como base de senso comum para as sociedades a partir das questões biológicas. Por isso, é primordial para esse estudo a separação dos conceitos de sexo e gênero na formulação da identidade.

Sobre a questão do sexo, Joana Maria Pedro (2005), traz a seguinte reflexão:

Em português, como na maioria das línguas, todos os seres animados e inanimados têm gênero. Entretanto, somente alguns seres vivos têm sexo. Nem todas as espécies se reproduzem de forma sexuada; mesmo assim, as palavras que as designam, na nossa língua, lhes atribuem um gênero. E era justamente pelo fato de que as palavras na maioria das línguas têm gênero, mas não têm sexo, que os movimentos feministas e de mulheres, nos anos oitenta, passaram a usar esta palavra "gênero" no lugar de "sexo". Buscavam, desta forma, reforçar a idéia de que as diferenças que se constatavam nos comportamentos de homens e mulheres não eram dependentes do "sexo" como questão biológica, mas sim eram definidos pelo "gênero" e, portanto, ligadas à cultura. (ibidem, p. 78).

Esta desconstrução da relação de gênero como algo ligado ao biológico se faz importante porque ela não explica as diferentes identidades, ou seja, do gênero que é definido pela cultura. Com base nas questões biológicas, os discursos são legitimados e estabelecidos para constituir os sujeitos. É o caso dos pais que vão ao médico para descobrir o sexo do bebê e, a partir da revelação do profissional da saúde, baseado no órgão genital, é dito se é menino ou menina. Esta fala vem carregada de uma constituição daquilo que é ser homem/mulher dentro da heteronormatividade e com isso, este sujeito nasce dentro de um discurso que já está dado e, desde seu primeiro dia de vida, vai se habituar a objetos, roupas e cores que são determinados para meninos (azul) e para meninas (rosa).

Do ponto de vista de dominação, as questões de gênero interferem profundamente nas relações de poder e sobre esta observação Joan Scott (1995) revela: 
O gênero é uma das referências recorrentes pelas quais o poder político foi concebido, legitimado e criticado. Ele se refere à oposição masculino/feminino e fundamenta ao mesmo tempo seu sentido. Para reivindicar o poder político, a referência tem que parecer segura e fixa fora de qualquer construção humana, fazendo parte da ordem natural ou divina. Desta forma, a oposição binária e o processo social das relações de gênero tornam-se, os dois, parte do sentido do poder, ele mesmo. Colocar em questão ou mudar um aspecto ameaça o sistema por inteiro (ibidem, p. 27).

Para atravessar esse sistema de poder, é importante desconstruir os caminhos predeterminados e tirar as pessoas de suas caixinhas, ou seja, deslocá-las do olhar de fixidez que coloca os sujeitos em categorias binárias como homem/mulher, masculino/ feminino ou heterossexual/homossexual. Por isso, desfazer os discursos que produzem esses sujeitos se faz essencial na atualidade, visto que as questões de gênero estão em debate e presentes na sociedade de forma latente e conflitante. É nesse sentido que a luta política, por meio de mecanismos de resistência, pode possibilitar uma travessia pelo sistema de poder para que se traga a visibilidade e a conquista por direitos, tendo nas artes e, especialmente no teatro, importantes instrumentos para que os discursos de enfrentamento e transformação sejam legitimados.

\section{As artes como espaço de resistência}

A busca por diferentes ferramentas de visibilidade é um fator importante para a conquista de direitos sociais por grupos minoritários. Por isso, entende-se, aqui, o teatro como espaço simbólico de interação e visibilidade para a luta pelas causas LGBTQIs.

Ao analisarmos a invisibilidade lésbica nas artes, veremos que apenas um estereótipo é apresentado, da mesma forma que a identidade mulher é vista de forma única. Dentro desta categoria existem outras divisões que reforçam o apagamento. É o caso das lésbicas afrodescendentes, invisibilizadas por duas identidades: a negra e a lésbica.

Dentro das artes, o pouco espaço ocupado pelas mulheres é representado majoritariamente pela heterossexualidade branca $^{8}$. Basta observar a quantidade de atrizes com este perfil em telenovelas e o papel que as negras ocupam nestas

\footnotetext{
8 "A pesquisadora Fernanda Bueno estudou as aberturas de novelas veiculadas pela Rede Globo em um intervalo de dez anos e chegou a um resultado surpreendente: as mulheres negras estão ausentes de 50 das 59 vinhetas analisadas - o que representa um sexto do espaço dedicado às mulheres brancas. $\mathrm{O}$ resultado é incompatível com os números do Instituto Brasileiro de Geografia e Estatística (IBGE), o que evidencia a discriminação na escolha das atrizes e personagens. Segundo o último censo, cerca de $54 \%$ da população brasileira é negra". Disponível em: <https://www.ceert.org.br/noticias/comunicacaomidia-internet/15920/a-cada-seis-aberturas-de-novela-com-mulheres-brancas-apenas-uma-temmulheres-negras> Acesso em: 23 nov. 2017.
} 
produções, a exemplo da novela O Outro Lado do Paraíso $^{9}$, que posteriormente insere a personagem em outro contexto social, em que de empregada doméstica passa a ser juíza e nesta posição, causa indignação aos preconceituosos.

Mesmo com esta transição da personagem, a questão da escravidão e desvalorização das mulheres negras dentro de produções artísticas ainda é constante e não muito diferente da história dos negros nos processos de colonização. Mediante este cenário, Ângela Davis (2016) aborda as questões que envolvem a mulher, raça e classe.

Proporcionalmente mais mulheres negras sempre trabalharam fora de casa do que as suas irmãs brancas. $\mathrm{O}$ enorme espaço que o trabalho ocupou na vida das mulheres negras, segue hoje um modelo estabelecido desde o início da escravatura. Como escravas, o trabalho compulsoriamente ofuscou qualquer outro aspecto da existência feminina. Parece assim, que o ponto de partida de qualquer exploração da vida das mulheres negras sob a escravatura começa com a apreciação do papel de trabalhadoras (ibidem, p. 10).

Por esse ângulo, vemos o arquétipo da negra por diversas vezes em papéis de empregadas domésticas, personagens que vivem afastados dos grandes centros urbanos e de classes sociais mais baixas. A identidade da mulher negra continua a ser marginalizada reforçando a posição de privilégios sociais das brancas.

Quando voltamos o olhar para o universo lésbico, compreendemos que as poucas produções televisivas com lésbicas no enredo apresentam atrizes brancas e bem sucedidas a exemplo da novela "Senhora do Destino" ${ }^{10}$, que traz no enredo um casal de mulheres com este perfil. Aqui é possível verificar que existe uma maneira com a qual as lésbicas têm sido inseridas na teledramaturgia brasileira e que precisa ser discutida, já que as questões raciais estão presentes nessas produções.

De modo geral, existe uma padronização criada para a lésbica nas produções televisivas, como tem acontecido com personagens gays apresentados, muitas vezes, de forma binária como vilão/mocinho. É o caso do personagem Félix da novela "Amor à Vida" ${ }^{11}$. Devido as frases de efeito e a postura de vilão, o personagem ganhou fama nas redes sociais, tornando-se assim uma celebridade. Porém, este tipo de construção nos leva a um lugar fixo, que estabelece um padrão a ser inserido com a finalidade de aceitação social.

9 Telenovela exibida na emissora Globo (2017) em que inicialmente, há uma situação de racismo vivenciada por meio de um romance entre uma jovem empregada doméstica (Interpretada pela atriz Érika Januza) e filho da patroa (Interpretado por Caio Paduan), cuja mãe (Eliane Giardini) não aceita o relacionamento. Disponível em: <http://kogut.oglobo.globo.com/ noticias-da-tv/novelas/ noticia/2017/og/eliane-giardini-sera-uma-mulher-racista-em-o-outro-lado-do-paraiso.html> Acesso em: 23 nov. 2017.

10 Novela criada por Aguinaldo Silva e apresentada em horário nobre pela emissora Rede Globo entre os anos de 2004 e 2005 .

11 Novela criada por Walcyr Carrasco, e que foi ao ar entre os anos de 2013 e 2014 em horário nobre. 
A questão de idade também é um fator determinante na apresentação das lésbicas em telenovelas. É o caso das personagens interpretados pelas atrizes Fernanda Montenegro e Nathália Timberg na novela Babilônia ${ }^{12}$, cujo beijo em horário nobre causou muitas críticas nas redes sociais.

A cena do folhetim foi o assunto mais comentado das redes sociais e da mídia em geral no Brasil no dia seguinte à sua exibição. O que chamou a atenção em mais uma polêmica envolvendo a exibição de demonstrações de afeto por parte de pessoas do mesmo sexo foi, dessa vez, o grau de agressividade nos comentários. Bem maior do que os dos beijos lésbicos de suas antecessoras. (PRAGMATISMO, 2015)..$^{13}$

A reação negativa do público revela o quanto o lesbianidade ainda é visto com o estigma do objeto de prazer masculino, já que produções com lésbicas jovens não tiveram o mesmo impacto na mídia e nas redes sociais como no caso das personagens de Babilônia.

Devido ao grande alcance dos trabalhos artísticos, é preciso pensar sobre as ferramentas e caminhos para a desconstrução desse lugar fixo onde estabeleceram um padrão uniforme para a lésbica. A exemplo estão os trabalhos fotográficos realizados pela ativista visual Zanele Muholi ${ }^{14}$, sul-africana que traz em seus retratos lésbicas e transgêneros, bem como as diferenças das africanas.

Figura 2
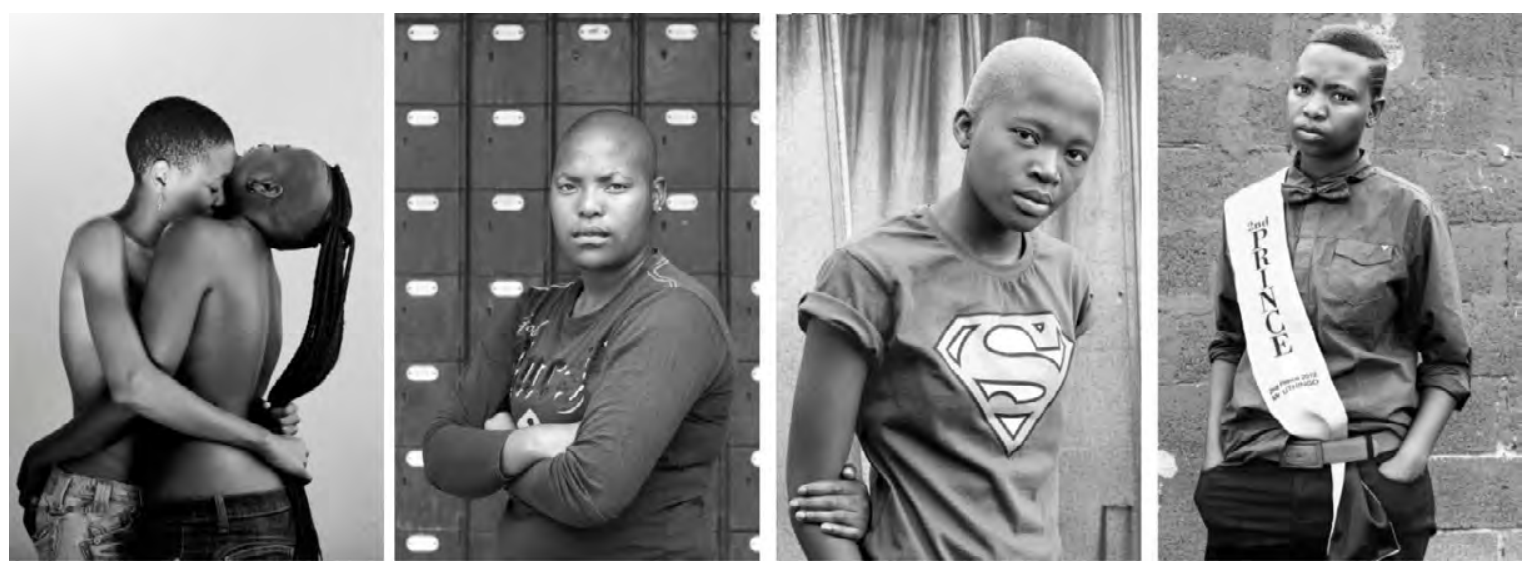

Fotos: Zanele Muholi ${ }^{15}$.

12 Novela criada pelos autores Gilberto Braga, Ricardo Linhares e João Ximenes Braga e foi ao ar em 2015 em horário nobre.

13 Disponível em:

<https://www.pragmatismopolitico.com.br/2015/o3/por-que-o-beijo-gay-entre-fernandamontenegro-e-nathalia-timberg-chocou-mais.html> Acesso em: 16 nov. 2017.

14 Disponível em: <https://revistazum.com.br/tv-zum/zanele-muholi/> Acesso em: 18 out. 2017.

15 The New York Times: Disponível em: <https://lens.blogs.nytimes.com/2014/o6/o9/photographinga-difficult-love-in-south-africa/> Acesso em: 23 nov. 2017. 
Por meio das fotografias, ela mostra que é possível documentar a existências lésbica negra para que elas possam ter as vidas cotidianas registradas. É o que afirma Natália Cabanillas (2016):

Dentro da produção - material ou visual - da vida da LGBTI está incluída uma maneira de inscrever a vida, de normalizar a sua existência, através de formas concretas de integração na vida comunitária (Free Gender ${ }^{16}$ ); e a criação de um regime de visualização que responde as narrativas visuais da brutalização e da vitimização dos corpos de mulheres lésbicas negras no país e no trabalho de Zanele Muholi. Esta linguagem visual normaliza e individualiza simultaneamente, usa o retrato como um recurso discursivo e a intimidade como espaço de transgressão. Neste plano, o Free Gender aposta no descentramento da sexualidade dissidente, restituição da totalidade da vida e "cotidianidade" do ser lésbico (ibidem, p. 942).

Este trabalho realizado por Zanele revela como é possível fazer um recorte, por meio da fotografia, e registrar o universo lésbico africano para que não exista o apagamento da existência dessas mulheres na história e que este registro fique para consulta das futuras gerações. Como manifestação artística, apresenta-se também um dos caminhos possíveis para que as lésbicas possam resistir e traz um exemplo de militância para combater o preconceito.

Nos filmes e livros, quando aparecem casais de mulheres, ou o destino de uma delas é a morte, ou uma delas trai a outra com outro homem (muitas vezes, deixando-a). Quando o amor entre duas mulheres é narrado por um homem, o mais provável é que o foco seja o erotismo; esquece-se, assim, do companheirismo, da luta e da complexidade feminina como pessoa e ser psicológico (MONTERASTELLI, 2017). ${ }^{17}$

Trabalhar as questões humanas dessas identidades por meio das artes é uma maneira de criar espaços de transgressão dos sujeitos que, ainda no século XXI, chocam e geram resistência. Este universo das imagens sul-africanas é aqui abordado porque as questões afrodescendentes fazem parte da cultura brasileira e traz uma reflexão de como as lésbicas, principalmente as negras, podem encontrar alternativas para combater a invisibilidade. Mediante esta perspectiva, questiona-se como é possível trabalhar a resistência em meio a identidades desconstruídas e invisibilizadas, senão por meio da luta e do ato público.

16 Free Gender - Organização de Mulheres Lésbicas Negras.

17 Disponível em: <http://www.vermelho.org.br/noticia/301173-1> Acesso em: 26 nov. 2017. 


\section{A desconstrução do sujeito}

As fotografias de Muholi mostram qual enquadramento a artista traz para seu trabalho. Ao retratar a identidade lésbica, ela avança para um processo de evidenciar as dessemelhanças entre as lésbicas negras e suas diferenças corpóreas. Nesse sentido, podemos refletir acerca de cada sujeito que, mesmo categorizado como "lésbica negra" é atravessado por diferentes identidades.

Se aproximarmos este olhar para o trabalho de Judith Butler (2002) podemos pensar na diversidade desses corpos lésbicos e o quanto a questão do racismo os colocam como corpos abjetos.

A abjeção de certos tipos de corpos, sua inaceitabilidade por códigos de inteligibilidade, manifesta-se em políticas e na política, e viver com um tal corpo no mundo é viver nas regiões sombrias da ontologia. Eu me enfureço com as reivindicações ontológicas de que códigos de legitimidade constroem nossos corpos no mundo; então eu tento, quando posso, usar minha imaginação em oposição a essa ideia (BUTLER, et al. 2002, p. 157) ${ }^{18}$.

A abjeção dos corpos mostra que não há uma inteligibilidade entre corpo, sexo e gênero, pois, a heteronormatividade imposta em nossa sociedade traz uma visão em que o corpo é o definidor do sexo (desejo) e logo, o gênero também se apresenta alinhado a esses definidores. Esta visão abarca o determinismo biológico que torna o corpo subjetivado pelo discurso.

A fixidez imposta pela heteronormatividade exclui a diferença. "Corpos que não importam são corpos abjetos. Tais corpos não são inteligíveis (um argumento epistemológico) e não têm uma existência legítima (um argumento político ou normativo)" (PRINS e MEIJER, 2002, p. 160). Sem essa legitimidade, não há representação política desses corpos. Portanto, os trabalhos artísticos, possibilitam a desconstrução desses discursos de fixidez ao colocar no campo da visibilidade os corpos marginalizados pela sociedade.

Se trouxermos a questão dos corpos abjetos para a categoria mulher, veremos que esses corpos também são colocados na condição de abjetos, principalmente se classificá-los como "mulheres próprias ou impróprias".

Eu acho que a abjeção tenta sinalizar o que permanece fora dessas oposições binárias, a ponto mesmo de possibilitar esses binarismos. Quem é considerada uma mulher imprópria? Quem passa a ser denominada imprópria no texto que a historiadora estuda? Que tipos de atos são classificados ou designados ou nomeados? E quais são tão inomináveis e inclassificáveis que se tornam impróprios à impropriedade, ficando fora do impróprio? (BUTLER et al. 2002, p. 165-166).

18 PRINS, Baukje e MEIJER, Irene Costera. Como os Corpos Se Tornam Matéria: Entrevista com Judith Butler. Rev. Estud. Fem. [online]. 2002, vol.10, n.1 [citado 2017-09- o6], pp.155-167. 
Logo, além das questões que envolvem o que é ou não ser mulher, existem as subdivisões que estabelecem as diferenças também entre as lésbicas, a exemplo de trejeitos, modos de vida, profissões, crenças, valores, enfim, uma gama de particularidades que as separam umas das outras. Isso também acontece com as mulheres cis heterossexuais, ${ }^{19}$ bem como os homens em suas diferentes categorias.

Ao trazermos esta reflexão para a dramaturgia, podemos pensar em como essas identidades que perpassam as lésbicas são retratadas, se não de uma forma estereotipada e fixa, muitas vezes como objeto de prazer dos homens como em filmes pornográficos. "Não é de hoje que sabemos que a sexualidade feminina é reprimida pela sociedade em que vivemos. O mercado erótico, em sua maioria, tem foco nas necessidades dos homens, ignorando ou deixando em segundo plano o interesse das mulheres" (SOUZA e ANDRADE, 2016, p. 2). A vulgarização da mulher e a exposição do sexo lésbico como objeto de prazer masculino se faz presente em diferentes produções artísticas reforçando a ideia de banalização dessas identidades.

A humanização desses sujeitos deve ser representada em cena, para que esta ideia de fetichização do sexo lésbico como objeto de prazer do homem heterossexual seja desconstruída. Ou seja, que estes trabalhos possam refletir acerca da realidade cotidiana para mostrar que lésbicas se constituem como casais, constroem famílias e muitas vezes, exercem a maternidade. Mas, para que essas identidades possam ser mostradas na cena, é preciso que lésbicas se reconheçam como tal, isto é, assumir o seu lugar de pertencimento, ao mesmo tempo em que exigir que suas identidades sejam reconhecidas e representadas.

Portanto, tratando-se de uma luta por direitos, se voltarmos os olhos para as lésbicas dentro do teatro, mesmo que não exista um movimento lésbico cultural equiparando-se aos movimentos lésbicos feministas, reconhecer-se como lésbica é posicionar-se politicamente. Assim, este sujeito mulher lésbica precisa ser representado nas artes dentro de suas inconsistências e em diferentes "contextos históricos”. Essa abordagem do universo lésbico, quando apresentada em cena, é uma oportunidade para que lésbicas possam se reconhecer em suas diferenças quanto sujeitos atravessados por diversas identidades.

\section{O Caso da Parada LGBTQI 2017 em São Paulo/SP}

Para levar este debate lésbico à cena, é preciso analisar o cenário atual do teatro LGBTQI. O reconhecimento das identidades lésbicas na cena paulistana é uma questão a ser observada porque durante os eventos que antecedem a Parada do Orgulho Gay, acontecem diferentes atividades culturais que fazem parte da agenda LGBTQI de São Paulo, principalmente porque a Parada é considerada um evento turístico que gera oportunidades para a visibilidade, fazendo parte do calendário oficial da cidade. No

19 Dentro das questões de gênero existem algumas nomenclaturas para explicar as diferentes identidades como a cis ou cisgênero que são pessoas que são designadas ao nascer a um determinado gênero e se identificam com ele. 
entanto, é apresentada uma separabilidade dentro do próprio movimento gay. É o caso da Caminhada de Mulheres Lésbicas e Bissexuais que aconteceu em julho de 2017. Por sentirem-se invisibilizadas pela própria militância gay, essas mulheres vão às ruas anualmente para serem reconhecidas e engajar uma luta pelo combate ao feminicídio, como foi o caso da $15^{\text {a }}$ edição que contou com o tema Luanas e Katianes. Quantas mais? Resistiremos! "em homenagem a Luana Barbosa dos Reis e Katiane Campos, duas mulheres brasileiras que foram brutalmente assassinadas, vítimas de lesbofobia e racismo no último ano (Brasil de Fato, 2017 ${ }^{20}$ )".

Além do protesto contra o feminicídio de lésbicas, foi possível observar a questão da violência durante a Parada do Orgulho Gay. Na edição de 2017, a imprensa testemunhou cenas de assédio. "A reportagem da CULT esteve na Paulista e presenciou cenas de casais lésbicos sendo ridicularizados enquanto se beijavam, meninas sendo coagidas a beijar rapazes 'de brincadeira' e muitos grupos de homens tocando, sem permissão, corpos de mulheres (CULT, 2017) $)^{21}$ ".

Esta banalização e agressão demonstram como as questões que envolvem as identidades lésbicas precisam ser discutidas durante este período de maior visibilidade das causas LGBTQIs. Porém, o teatro apresentado no mesmo período em 2017, trouxe temáticas voltadas ao universo gay, queer e trans. Entre os 19 espetáculos divulgados pelo Guia Gay São Paulo², as peças apresentaram assuntos como contos homoeróticos, homossexual envelhecido, jovem com HIV, transexualidade, aceitação da homossexualidade, racismo, homofobia, identidade degênero, violência doméstica, bem como aceitação das diferenças, temas que foram contextualizados por histórias que não abordaram o universo lésbico.

Mesmo com o teatro como ferramenta de militância LGBTQI dentro de um evento com considerável visibilidade, a representatividade das temáticas que envolvem a identidade lésbica não se fez presente. Os tópicos voltados aos gays, trans e queers trouxeram ao debate assuntos que não abordam a violência sofrida por muitas lésbicas e que foram retratadas em outras manifestações, durante a Parada, como a Caminhada de Mulheres.

Nesse sentido, é possível ver que existe uma militância gay que utiliza o teatro como espaço de debate para as questões que envolvem a homossexualidade, mas que não tem realizado trabalhos que abordem a desconstrução de estigmas e a fixidez da identidade lésbica.

20 Disponível em: <https://www.brasildefato.com.br/2017/06/15/as-mulheres-sao-invisibilizadas-nomovimento-lgbt-afirmam-militantes/> Acesso em: 25 out. 2017.

21 Disponível em:<https://revistacult.uol.com.br/home/casos-de-assedio-e-violencia-parada-lgbt/> Acesso em: 25 out. 2017.

22 Disponível em: <http://www.guiagaysaopaulo.com.br/1/n--para-aplaudir!-sp-tem-pecas-lgbt-nasemana-da-parada!--12-o6-2017--4729.htm> Acessado em: 28 out. 2017. 


\section{Considerações finais}

A luta por representatividade das lésbicas na sociedade é uma questão fundamental a ser debatida para que as causas da invisibilidade sejam revistas, reconsideradas e transformadas. Nesse contexto, as artes, principalmente o teatro, se apresentam como um meio para unir diferentes mulheres lésbicas que, através destas manifestações artísticas, podem levar para a cena as inúmeras identidades que as constituem, bem como encontrar espaços de ocupação para que seus direitos sejam reivindicados.

Entretanto, devido à quantidade considerável de espetáculos teatrais voltados para o universo gay, como fica demonstrado no estudo sobre a Parada do Orgulho Gay, SP, em 2017, é possível observar que há pouco espaço para as discussões lésbicas no teatro, bem como nas produções de telenovelas que ainda inserem a lésbica de forma estereotipada, sem levar em consideração as diferentes identidades que atravessam o sujeito pós-moderno. Logo, a reflexão acerca das diferentes identidades também é importante para que a lésbica não seja estereotipada, ou ainda, mais invisibilizada do que já é atualmente.

A criação de grupos Mulheres do Teatro Brasil na rede social Facebook, mostra como há uma necessidade das mulheres ocuparem espaços de direito que ainda são representados por homens. Ao mesmo tempo, é um local para legitimar a força política dessa reunião de mulheres atravessadas por diferentes identidades, mas que no contexto da militância e posicionamento dentro do campo das artes, apresentam-se de forma a fixar o sujeito mulher em busca da ocupação de maiores espaços de trabalho e atuação. Esta representatividade aparece como um movimento de resistência.

Se olharmos para as imagens fotográficas de Zanele Muholi, veremos que, mesmo dentro da identidade lésbica negra, há outras particularidades que as separam e as definem. Esse exemplo demonstra como os sujeitos são fluídos e não se encaixam na forma binária de ver o gênero como gay/lésbica.

Essas diferentes identidades podem ser representadas no teatro por meio de dramaturgias que retratam este universo de desconstrução. Ou seja, por meio de personagens e do retrato da vida cotidiana, é possível desconstruir as formas binárias impostas pela heteronormatividade e retratar as diferentes identidades lésbicas em cena. Ao mesmo tempo em que o teatro abre as portas para o debate entre artista/ público, ele oferece o espaço para as vozes serem ditas, ouvidas e interpretadas. Logo, muitos discursos podem ser desconstruídos, principalmente do ponto de vista da biologia, e combater manifestações violentas como as de homofobia ou lesbofobia.

As questões de gênero do ponto de vista do determinismo biológico estão presentes no entendimento da maioria das pessoas de nossa sociedade e tem sido um assunto bastante relevante nos debates dos últimos tempos. Os discursos das Ciências Biológicas têm sido legitimados por algumas religiões que utilizam deste aparato para justificarem as definições de homem/mulher com base no órgão genital que estão dadas como verdade pela biologia. Esses discursos precisam ser revistos porque são 
motivos de ódio e até de agressões contra todos os LGBTQIs. Além dos altos índices de feminicídios $^{23}$ no país, o Brasil é o lugar onde mais se mata transexuais no mundo ${ }^{24}$. $\mathrm{O}$ conservadorismo tem se mostrado presente nas esferas políticas, sociais e religiosas de maneira que manifestações artísticas têm sido censuradas por um grupo de conservadores. Dentro deste cenário, é preciso pensar os aspectos da humanidade e dos direitos sociais igualitários da perspectiva universal e dentro de particularidades. Ou seja, de forma global e individual, levando-se em consideração que para os sujeitos há diferentes enquadramentos. Por isso, o teatro apresenta-se como uma ferramenta para que novas conjunturas sejam feitas e que a vida lésbica seja representada por suas diferentes identidades.

Este artigo aponta para caminhos notórios de visibilidade lésbica, combate ao preconceito e aceitabilidade das diferenças no século XXI, principalmente dentro da realidade brasileira. Ele traz o chamamento para o debate das questões que podem mobilizar as lésbicas dentro das artes para combater o machismo, por meio de novas dramaturgias produzidas e espetáculos que retratem as diferentes identidades. Ao mesmo tempo, aponta para o aprofundamento de pesquisas acadêmicas que analisem o universo lésbico nas artes por diferentes perspectivas.

Essas multiplicidades de identidades encontradas na diversidade podem ser trabalhadas para que personagens lésbicos estejam mais presentes na vida cotidiana e com isso, criar significativas transformações.

\section{Referências}

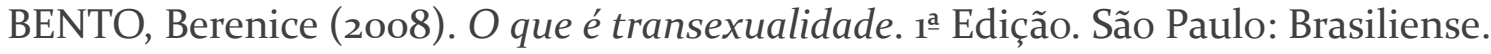

BUTLER, Judith (2010). Marcos de Guerra: Las Vidas Lloradas. 1aㅡ Edição. México: Editorial Paidós Mexicana, S. A.

BRITTO, Clóvis Carvalho; MOREIRA, Núbia Regina (2014). Dossiê Mulheres e Expressões Artísticas. Arquivos do CMD, n. 2, 2: p.7-13, jul-dez.

CABANILLAS, Natália (2016). Normalizar La Existencia Lesbiana. Revista Estudos Feministas, n. 24, 3: p.941-958. set-dez.

23 "Segundo a Organização Mundial da Saúde (OMS), o número de assassinatos chega a 4,8 para cada 100 mil mulheres. O Mapa da Violência de 2015 aponta que, entre 1980 e 2013, 106.093 pessoas morreram por sua condição de ser mulher. As mulheres negras são ainda mais violentadas. Apenas entre 2003 e 2013 , houve aumento de $54 \%$ no registro de mortes, passando de 1.864 para 2.875 nesse período. Muitas vezes, são os próprios familiares $(50,3 \%)$ ou parceiros/ex-parceiros $(33,2 \%)$ os que cometem os assassinatos." Disponível em: <http://agenciabrasil.ebc.com.br/direitos-humanos/noticia/2017-o8/ taxa-de-feminicidios-no-brasil-e-quinta-maior-do-mundo> Acesso em: 16 nov. 2017.

24 "O Brasil matou ao menos 868 travestis e transexuais nos últimos oito anos, o que o deixa, disparado, no topo do ranking de países com mais registros de homicídios de pessoas transgêneras”. Disponível em: <http://especiais.correiobraziliense.com.br/brasil-lidera-ranking-mundial-de-assassinatos-de-transexuais> Acesso em: 15 nov. 2017. 
CLAESEN, Marcio (2017). Para Aplaudir! SP tem 19 peças LGBT na semana da Parada! Guia Gay São Paulo Disponível em: <http://www.guiagaysaopaulo.com.br/1/n--paraaplaudir!-sp-tem-pecas-lgbt-na-semana-da-parada!--12-o6-2017--4729.htm> Acesso em: 28 out. 2017 .

D’ANGELO, Helô e PARRA, Nathalia (2017). Mulheres relatam casos de assédio e violência durante Parada LGBT. CULT. Disponível em: <https://revistacult.uol.com. br/home/casos-de-assedio-e-violencia-parada-lgbt/> Acesso em: 25 out. 2017.

DAVIS, Angela (2016). Mulher, Classe e Raça. 1ª Edição. São Paulo: Boitempo.

FOUCAULT, Michel (1995). O Poder e o Sujeito. In: DREYFUS, Hubert. \& RABINOW, Paul. Michel Foucault, uma trajetória filosófica: para além do estruturalismo e da hermenêutica. $1^{\underline{a}}$ Edição. Rio de Janeiro: Forense Universitária. p. 231-249.

FOUCAULT, Michel (1996). A Ordem do Discurso. $3^{\text {a }}$ Edição. São Paulo: Edições Loyola.

FOUCAULT, Michel (1988). História da Sexualidade 1: A Vontade de Saber. 13 $3^{\underline{a}}$ Edição. Rio de Janeiro: Edições Graal.

GIOVANAZ, Daniel (2017). A cada seis aberturas de novela com mulheres brancas, apenas uma tem mulheres negras. Centro de Estudos das Relações de Trabalho e Desigualdade - CEERT. Disponível em: <https://www.ceert.org.br/noticias/ comunicacao-midia-internet/15920/a-cada-seis-aberturas-de-novela-commulheres-brancas-apenas-uma-tem-mulheres-negras> Acesso em: 23 nov. 2017.

HALL, Stuart (2014). A Identidade Cultural na Pós-Modernidade. 1aㅡ Edição. Rio de Janeiro: Lamparina.

MARINHO, Mariana (2017). No clima da Parada do Orgulho LGBT, peças discutem diversidade sexual e homofobia. Folha de São Paulo. Disponível em: <http://guia. folha.uol.com.br/teatro/2017/o6/no-clima-da-parada-do-orgulho-lgbt-pecasdiscutem-diversidade-sexual-e-homofobia.shtml>. Acesso em: 03 dez. 2017.

MARTINS, Helene (2017). Taxa de feminicídios no Brasil é a quinta maior do mundo. EBC Agência Brasil. Disponível em: <http://agenciabrasil.ebc.com.br/direitoshumanos/noticia/2017-o8/taxa-de-feminicidios-no-brasil-e-quinta-maior-domundo> Acesso em: 16 nov. 2017.

MISKOLCI, Richard (2003). Reflexões sobre normalidade e desvio social. Revista Estudos de Sociologia. n.7, 13/14: p.109-126. 
MONTERASTELLI, Alessandra e SERAFINI, Mariana (2017). O mundo das artes ocupado por lésbicas e o desafio da visibilidade. Portal Vermelho. Disponível em: <www.vermelho.org.br/noticia/301173-1> Acesso em: 26 nov. 2017.

NICHOLSON, Linda (200o). Interpretando o Gênero. Revista Estudos Feministas, n. 8, 2: p. 9-42.

PEDRO, Joana Maria (2005). Traduzindo o debate: o uso da categoria gênero na pesquisa histórica. História. n. 24, 1: p.77-98.

PRINS, Baukje; MEIJER, Irene Costera (2002). Como os Corpos Se Tornam Matéria: Entrevista com Judith Butler. Revista Estudos Feministas. n. 10, 1: p.155-167.

REDAÇÃO (2015). Por que o beijo gay entre Fernanda Montenegro e Nathália Timberg chocou mais? Pragmatismo Político. Disponível em: <https://www. pragmatismopolitico.com.br/2015/o3/por-que-o-beijo-gay-entre-fernandamontenegro-e-nathalia-timberg-chocou-mais.html> Acesso em: 16 nov. 2017.

ROSALLES, Marianna. (2017). As mulheres são invisibilizadas no movimento LGBT, afirmam militantes. Brasil de Fato. Disponível em: <https://www.brasildefato. com.br/2017/o6/15/as-mulheres-sao-invisibilizadas-no-movimento-lgbt-afirmammilitantes/> Acesso em: 25 out. 2017.

SANTOS, Rafaela (2017). O outro lado do paraíso: Eliane Giardini será uma mulher racista. O Globo. Disponível em: <http://kogut.oglobo.globo.com/noticias-da-tv/ novelas/noticia/2017/o9/eliane-giardini-sera-uma-mulher-racista-em-o-outro-ladodo-paraiso.html> Acesso em: 23 nov.2017.

SCOTT, Joan Wallach (1995). Gênero: Uma Categoria Útil para Análise Histórica. Educação E Realidade. n. 20, 2: p. 71-99. Jul-dez.

SOUZA, Fabiola Ursula Gomes de Souza; ANDRADE, Emile Cardoso Andrade (2016). "A Mulher em Narrativa: O Erotismo Feito por Elas e para Elas". In: CONGRESSO DE ENSINO, PESQUISA E EXTENSÃO DA UEG, 3, Pirenópoli. Anais do Congresso de Ensino, Pesquisa e Extensão da UEG, Pirenópolis: CEPE. Disponível em: <http:// www.anais.ueg.br/index.php/cepe/article/view/7453/4943> Acesso em: 23 nov. 2017.

TEATRO, Mulheres do (2017). Facebook. Disponível em: <https://www.facebook. com/groups/mulheresdoteatrobrasil/ ?multi_permalinks=354747371633866\&notif_ $\mathrm{id}=1507728852465922 \&$ notif_t=group_activity> Acesso em: 12 out. 2017. 
ZUM, TV (2017). Fotografia e ativismo: Zanele Muholi e as mulheres negras lésbicas e transgêneros da África do Sul. ZUM Revista de Fotografia. Disponível em: <https:// revistazum.com.br/tv-zum/zanele-muholi/>. Acesso em: o1 nov. 2017.

Recebido: 11.12.2017

Aceito: 29.05.2018 